Article

\title{
Performance-Based Reliability Estimates for Highway Bridges Considering Previous Inspection Data
}

\author{
Won-Ho Heo
}

Korea Institute of Engineering and Building Technology, Gyeonggi-Do 10223, Korea; wonhoheo@kict.re.kr; Tel.: +82-31-995-0836

Received: 21 December 2019; Accepted: 5 March 2020; Published: 9 March 2020

\begin{abstract}
This paper proposes a performance-based resistance deterioration model that reflects the site environment and inspection data for highway bridges. Traffic characteristics and corrosive environment are considered as the site environment. The corrosive environments and traffic characteristics are classified into three categories, namely mild, normal, and severe for the former and light, normal, and heavy for the latter. The deterioration of the resistance capacity due to corrosive environments is evaluated considering both the service period and the concrete crack widths in the pre-stressed concrete (PSC) girder and the reinforced concrete (RC) slab. The deterioration model of the resistance capacity is calibrated by combining the performance degradation model. The performance degradation model is also calibrated using previous bridge inspection results from the standard performance degradation model, which has been developed based on the large amount of data available on many pre-stressed concrete-I (PSC-I) type girder bridges. The developed performance-based resistance deterioration model is used to evaluate the reliability of a bridge in the future. The results show that the performance inspection outcomes, either based on the current status or lifetime inspection history, are critical in estimating the future degradation of the reliability level, inherent to the bridge.
\end{abstract}

Keywords: performance-based resistance deterioration model; highway bridge; inspection data; performance degradation; reliability

\section{Introduction}

Bridges play a significant role in national economic development and public welfare. Damage to major bridges results in direct losses such as loss of life and damage to structures, and indirect losses such as loss to the local economy. Therefore, bridges should be constructed and maintained to satisfy and retain the requisite performance.

Ang et al. [1] have proposed a basic reliability theory to evaluate the safety of structures. Kameda and Koike [2] proposed the concept of evaluating the safety of existing structures by applying the theory of reliability and considering the remaining strength and loads of the deteriorated structural members. Yang et al. [3] presented a model based on a lifetime function to predict the improvement in the reliability of a damaged bridge that required maintenance. Okasha and Frangopol [4] presented genetic algorithms and proposed maintenance strategies for structures considering their reliability and redundancy. Wang et al. [5] proposed an approximate method for assessing the impact of structural deterioration and non-stationary live loads on structures. Gua et al. [6] evaluated the total life-cycle benefits of using high performance concrete with internal curing bridge decks compared to normal concrete bridge decks in a transportation network. However, these studies have limited scope for analyzing the performance degradation by reflecting traffic characteristics, the corrosive environment, and inspection data of the actual bridge. 
This study deals with the safety and reliability analysis of the performance of structures, and a performance-based resistance deterioration model is presented to evaluate the reliability of bridge reflecting the site's environment, such as traffic characteristics and corrosive environments. This model is developed by combining the performance degradation model based on the bridge inspection results and the deterioration model of resistance capacity, considering the corrosive environments presented in Kim et al. [7].

\section{Basic Resistance Deterioration and Reliability Analysis}

The bridge under consideration was to be used as a two-lane expressway and comprised a single span that was $15 \mathrm{~m}$ in width. Table 1 and Figure 1 present the data specifications and cross-sectional profiles of the representative bridge at the mid-span [8]. The basic resistance capacity of the pre-stressed concrete-I (PSC-I) girder bridge was evaluated by using the flexural strength equation from the load-and-resistance factor design (LRFD) bridge design specifications [9].

Table 1. Section properties of the pre-stressed concrete-I (PSC-I) bridge.

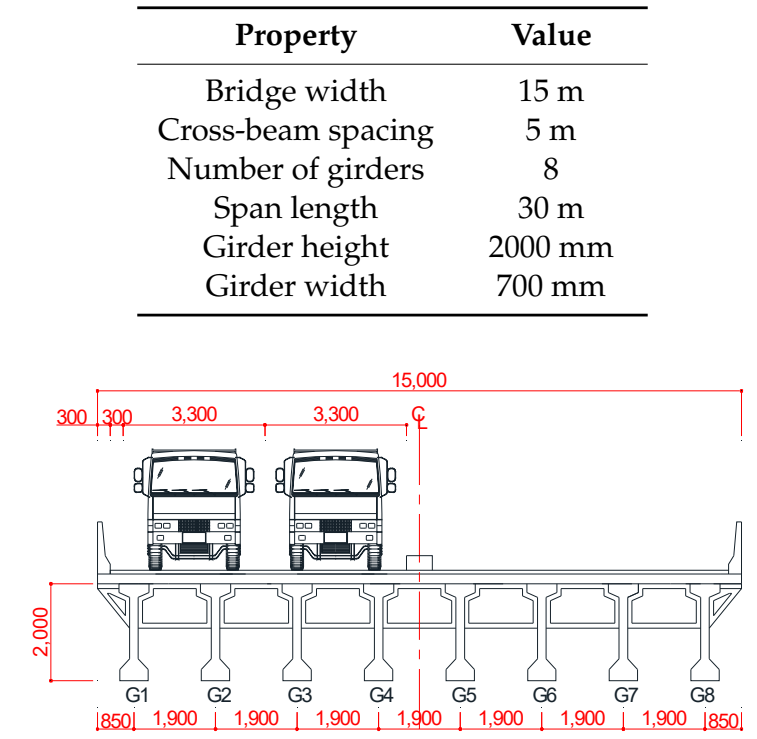

Figure 1. Cross-section of the PSC-I bridge at the mid-span (mm).

The initiation time for the performance of the structure to deteriorate was calculated using the improved chloride diffusion equations of Kwon et al. [10]. Table 2 presents the corrosive parameters used in the analysis [7].

Table 2. Description of corrosive parameters for various corrosive environments.

\begin{tabular}{cccc}
\hline Parameter & Mild & Normal & Severe \\
\hline Surface chloride amount & $2.0 \mathrm{~kg} / \mathrm{m}^{3}$ & $3.5 \mathrm{~kg} / \mathrm{m}^{3}$ & $8.5 \mathrm{~kg} / \mathrm{m}^{3}$ \\
Water-cement ratio & 0.4 & 0.4 & 0.4 \\
Diffusion coefficient & $2.18 \times 10^{-12} \mathrm{~m}^{2} / \mathrm{s}$ & $3.87 \times 10^{-12} \mathrm{~m}^{2} / \mathrm{s}$ & $7.63 \times 10^{-12} \mathrm{~m}^{2} / \mathrm{s}$ \\
Penetration ratio & 3.7 & 5 & 8.9 \\
\hline
\end{tabular}

Damage to the materials comprising the cross-sectional area of the bridge structure affects the resistance capacity of the bridge directly. The effective area of the steel reinforcement decreases when the steel is corroded by chloride penetration. In this study, the decrease in the effective cross-section by corrosion of the reinforced steel of the floor plate and girder was considered. The uncertainty of the dead load was modeled by applying the statistical characteristics of the dead load suggested by Withiam et al. [11]. The statistical characteristics were taken from the National Cooperative Highway 
Research Program 368 (NCHRP 368) [12]. The material properties of concrete and steel structures were taken from Nowak and Szerszen [13]. The probabilistic characteristics of the resistance capacity were estimated through a Monte Carlo simulation, which was run 100,000 times. The estimated basic deterioration model of resistance capacity was used as the basic model in Sections 3.2 and 4.1. In this study, to apply the live load effect, an extreme annual load that reflects the actual traffic characteristics was referenced, as listed in $[14,15]$. Table 3 presents the probabilistic characteristics of the vehicle weight model: mobile cars (P), buses (B), mid-size trucks (T), heavy trucks (TT), and semi-trailers (ST). The first mode (1) indicates the empty or lightly-loaded condition, and the second mode (2) represents the heavily-loaded condition. An annual average daily traffic (AADT) of 10,000 along with heavy vehicle proportion of $15 \%$ was set as the light traffic characteristics; an AADT of 20,000 with heavy vehicle proportion of $25 \%$ was set as the normal traffic characteristics; an AADT of 40,000 with heavy vehicle proportion of $35 \%$ was set as the heavy traffic characteristics.

Table 3. Probabilistic characteristics of the vehicle weight model [14,15].

\begin{tabular}{|c|c|c|c|c|c|c|c|}
\hline \multirow{2}{*}{$\begin{array}{l}\text { Vehicle } \\
\text { Model }\end{array}$} & \multirow{2}{*}{ Mode } & \multirow{2}{*}{$\begin{array}{c}\text { Distribution } \\
\text { Type }\end{array}$} & \multicolumn{2}{|c|}{ Coefficients } & \multirow{2}{*}{$\begin{array}{l}\text { Min. } \\
\text { (Tons) }\end{array}$} & \multirow{2}{*}{$\begin{array}{l}\text { Max. } \\
\text { (Tons) }\end{array}$} & \multirow{2}{*}{$\begin{array}{l}\text { Correction } \\
\text { Coefficients }\end{array}$} \\
\hline & & & $\mu, \lambda$ & $\sigma, \zeta$ & & & \\
\hline $\mathrm{P}$ & 1 & L-N & 0.398 & 0.317 & 0.7 & 5.0 & 1.0000 \\
\hline \multirow{2}{*}{ B } & 1 & Normal & 4.089 & 1.020 & 1.4 & 17.1 & 0.0980 \\
\hline & 2 & Normal & 11.552 & 1.542 & 4.0 & 24.0 & 0.9020 \\
\hline \multirow{2}{*}{$\mathrm{T}$} & 1 & L-N & 1.338 & 0.620 & 1.25 & 24.1 & 0.7330 \\
\hline & 2 & L-N & 2.721 & 0.221 & 1.25 & 40.0 & 0.2945 \\
\hline \multirow{2}{*}{$\mathrm{TT}$} & 1 & L-N & 2.467 & 0.178 & 7.3 & 41.3 & 0.2190 \\
\hline & 2 & L-N & 3.253 & 0.203 & 7.3 & 62 & 0.7818 \\
\hline \multirow{2}{*}{ ST } & 1 & Normal & 18.541 & 3.000 & 11.3 & 63.4 & 0.2600 \\
\hline & 2 & L-N & 3.420 & 0.225 & 59.7 & 90 & 0.7421 \\
\hline
\end{tabular}

The reliability of a representative bridge was analyzed based on the limit state equation by Kim et al. [7] given below. The load factor in Equation (1) represents the moment exerted by each load, and the resistance factor represents the flexural strength of the structure:

$$
g=R_{f}-D_{1}-D_{2}-L L(1+I M),
$$

where $R_{f}$ is the resistance capacity (flexural strength), $D_{1}$ is the load effect due to the girder, $D_{2}$ is the load effect due to the barrier, sidewalk blocks, and pavement, $L L$ is the load effect due to the live load, and $I M$ is the impact coefficient.

\section{Performance-Based Resistance Deterioration Model}

\subsection{Standard Performance Degradation Model}

The standard performance degradation models proposed for domestic bridges in Korea by Korea Infrastructure Safety and Technology Corporation (KISTEC) [16] are used to estimate the degradation of the target bridge members over time. In this study, it is assumed that the condition of a bridge member is closely related to the performance of the bridge. The standard performance degradation models for bridge members are adopted to develop the performance degradation model of the bridge. Equations (2) and (3) by KISTEC [16] present the standard performance degradation models of the RC slab and PSC-I girder, respectively.

$$
\begin{aligned}
& y_{\text {slab }}=-0.00027502 x^{3}+0.00957326 x^{2}-0.19328448 x+5 \\
& y_{P S C}=-0.00017159 x^{3}+0.00700464 x^{2}-0.16058476 x+5
\end{aligned}
$$


where, $y_{\text {slab }}$ represents the condition of the RC slab, $y_{P S C}$ represents the condition level of the PSC-I girder, and $x$ is the service life of the structure (year).

Figure 2 shows the standard performance degradation models for the bridge members. Levels A-E are substituted with 5-1, respectively. Tables 4 and 5 summarize the evaluation criteria for the condition of the RC slab and PSC-I girder, respectively. Level A refers to the best condition, and level $\mathrm{E}$ refers to the lowest condition.

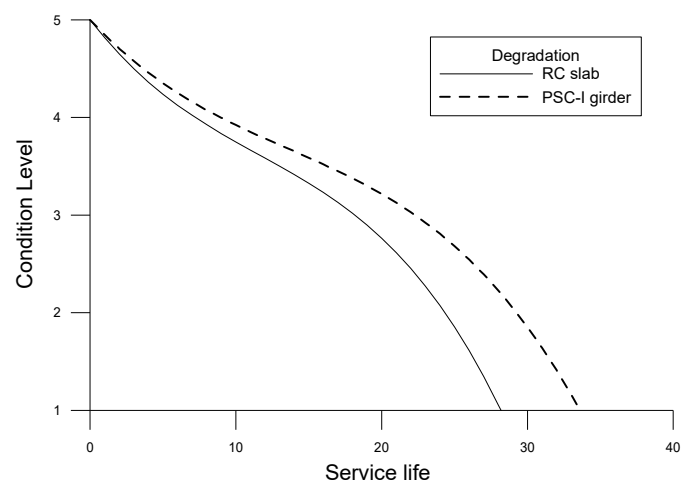

Figure 2. Condition level curves based on the standard performance degradation model.

Table 4. Condition level evaluation criteria of the reinforced concrete (RC) slab [17].

\begin{tabular}{ccc}
\hline Level & $\begin{array}{c}\text { Crack Width } \\
(\boldsymbol{w}, \mathbf{m m})\end{array}$ & $\begin{array}{c}\text { Surface Damage Rate } \\
\left(\boldsymbol{D}_{\boldsymbol{s}}, \mathbf{\%}\right)\end{array}$ \\
\hline $\mathrm{A}$ & $w<0.1$ & - \\
$\mathrm{B}$ & $0.1 \leq w<0.3$ & $D_{s}<2$ \\
$\mathrm{C}$ & $0.3 \leq w<0.5$ & $2 \leq D_{s}<10$ \\
$\mathrm{D}$ & $0.5 \leq w<1.0$ & $10 \leq D_{s}$ \\
$\mathrm{E}$ & $1.0 \leq w$ & Serious damage \\
\hline
\end{tabular}

Table 5. Condition level evaluation criteria of the PSC-I girder [17].

\begin{tabular}{ccc}
\hline Level & $\begin{array}{c}\text { Crack Width } \\
(\boldsymbol{w}, \mathbf{m m})\end{array}$ & $\begin{array}{c}\text { Surface Damage Rate } \\
\left(\boldsymbol{D}_{\boldsymbol{s}}, \boldsymbol{\%}\right)\end{array}$ \\
\hline $\mathrm{A}$ & - & - \\
$\mathrm{B}$ & $w<0.2$ & $D_{s}<2$ \\
$\mathrm{C}$ & $0.2 \leq w<0.3$ & $2 \leq D_{s}<10$ \\
$\mathrm{D}$ & $0.3 \leq w<0.5$ & $10 \leq D_{s}$ \\
$\mathrm{E}$ & $0.5 \leq w$ & Serious damage \\
\hline
\end{tabular}

Although it is valid to estimate the degradation trend of bridge members using Equations (2) and (3), these equations are believed to have limitations while considering a variety of site environments. It is not reasonable to analyze the degradation tendencies of bridge members with different site environment variables using this standard performance degradation model in the same manner. Therefore, the standard performance degradation model must be calibrated, considering the inspection results of the condition of the bridge.

\subsection{Process of Performance-Based Resistance Deterioration Modeling}

Figure 3 shows the calibration process of the standard performance degradation model and development process of the performance-based resistance deterioration model.

Step 1 consists of calibrating the standard performance degradation model using previous inspection results. Figure 4 shows the Step 1 for calibrating the standard performance degradation model. The standard performance degradation model was calibrated via regression analysis using the 
results from a previous inspection of bridge members, shown in Table 6 (1-W) and Table 7 (2-W). Before carrying out this step, it is necessary to recognize the bridge's tendency to degrade from the initial condition after the completion of bridge construction. The first lowered condition level in previous inspections is referenced as the point for calibration for the standard degradation model. The example of calibrating the standard performance degradation model is presented in Section 3.3.

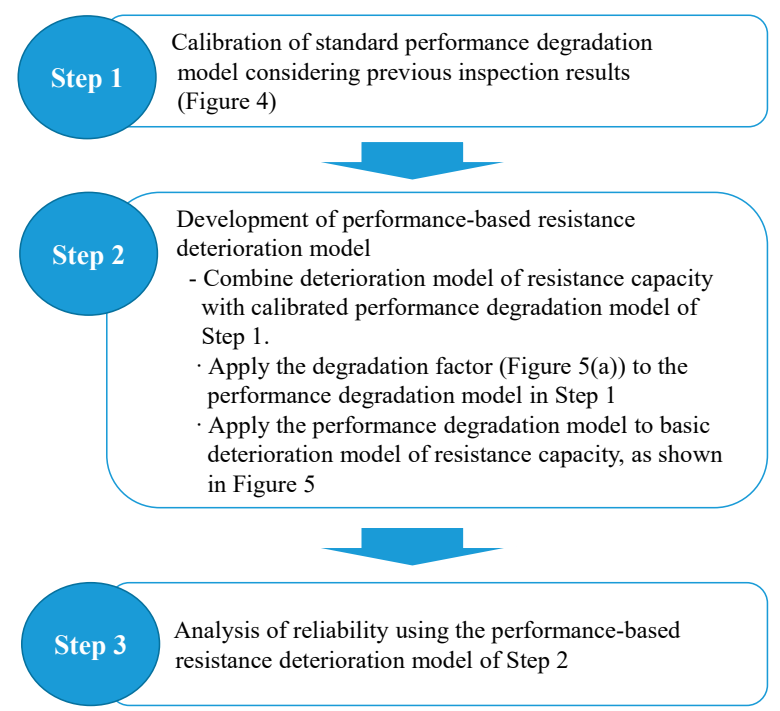

Figure 3. Process of performance-based resistance deterioration modeling.

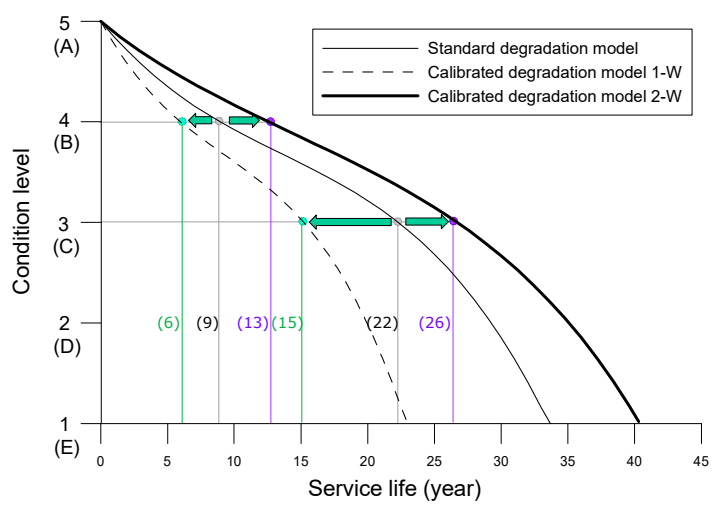

Figure 4. Example of a calibrated performance degradation model.

Table 6. Condition level of an RC slab and PSC-I girder (inspection type 1).

\begin{tabular}{ccccccccccc}
\hline & Bridge Member & \multicolumn{7}{c}{ Year of Condition Inspection } \\
\cline { 2 - 9 } & $\mathbf{2 *}$ & $\mathbf{4}^{*}$ & $\mathbf{6}^{*}$ & $\mathbf{8}^{*}$ & $\mathbf{1 0}$ & $\mathbf{1 1} *$ & $\mathbf{1 3}$ & $\mathbf{1 5}^{*}$ & $\mathbf{1 6} \mathbf{6}^{* *}$ \\
\hline $\begin{array}{c}\text { RC } \\
\text { slab }\end{array}$ & $\begin{array}{c}\text { With previous } \\
\text { inspection (1-W) } \\
\text { Without previous } \\
\text { inspection (1-W/O) }\end{array}$ & A & A & B & B & B & B & C & C & C \\
\hline $\begin{array}{c}\text { PSC-I } \\
\text { girder }\end{array}$ & $\begin{array}{c}\text { With previous } \\
\text { inspection (1-W) } \\
\text { Without previous } \\
\text { inspection (1-W/O) }\end{array}$ & A & A & B & B & B & B & B & C & C \\
\hline
\end{tabular}

* Precision inspection, ${ }^{* *}$ precision safety diagnosis. 
Table 7. Condition level of an RC slab and PSC-I girder (inspection type 2).

\begin{tabular}{|c|c|c|c|c|c|c|c|c|c|c|c|c|c|c|c|c|c|}
\hline \multirow{2}{*}{\multicolumn{2}{|c|}{ Bridge Member }} & \multicolumn{16}{|c|}{ Year of Condition Inspection } \\
\hline & & $2 *$ & $4 *$ & 6 * & $8^{*}$ & 10 * & 11 ** & $13 *$ & $15^{*}$ & $16 * *$ & 18 * & $20 *$ & $21 * *$ & $23 *$ & 25 * & $26 * *$ & 28 * \\
\hline \multirow{2}{*}{$\begin{array}{l}\text { RC } \\
\text { slab }\end{array}$} & With previous inspection $(2-\mathrm{W})$ & A & A & A & B & B & B & B & B & B & B & $\mathrm{C}$ & $\mathrm{C}$ & $\mathrm{C}$ & $\mathrm{C}$ & $\mathrm{C}$ & $\mathrm{C}$ \\
\hline & Without previous inspection $(2-\mathrm{W} / \mathrm{O})$ & - & - & - & - & - & - & - & - & - & - & - & $\mathrm{C}$ & - & - & - & $\mathrm{C}$ \\
\hline \multirow{2}{*}{$\begin{array}{l}\text { PSC-I } \\
\text { girder }\end{array}$} & With previous inspection $(2-W)$ & A & $\mathrm{A}$ & A & $\mathrm{A}$ & A & A & B & B & B & B & B & $\mathrm{B}$ & $\mathrm{B}$ & $\mathrm{B}$ & $\mathrm{C}$ & $\mathrm{C}$ \\
\hline & Without previous inspection $(2-\mathrm{W} / \mathrm{O})$ & - & - & - & - & - & - & - & - & - & - & - & B & - & - & - & $\mathrm{C}$ \\
\hline
\end{tabular}

* Precision inspection, ${ }^{* *}$ precision safety diagnosis. 
Step 2 is the process of applying the calibrated performance degradation model to the basic model (basic deterioration model of resistance capacity) presented in Section 2. The degradation factors evaluated for the calibrated performance degradation model (Figure 5a) are then reflected in the basic resistance model (Figure 5b-1st part). In Figure 5a no degradation is assumed for condition level $\mathrm{A}$ and $25 \%$ degradation is assumed for condition level $\mathrm{E}$. In addition, a linear degradation model is adopted from A to E. Figure $5 \mathrm{~b}$ shows the result of the calibrated resistance degradation model combined with the basic deterioration model of resistance capacity for up to 75 years without any repair on the deteriorated members. The performance-based resistance deterioration model developed through Steps 1 and 2 is used for the lifetime reliability analysis in Step 3 (Section 4).

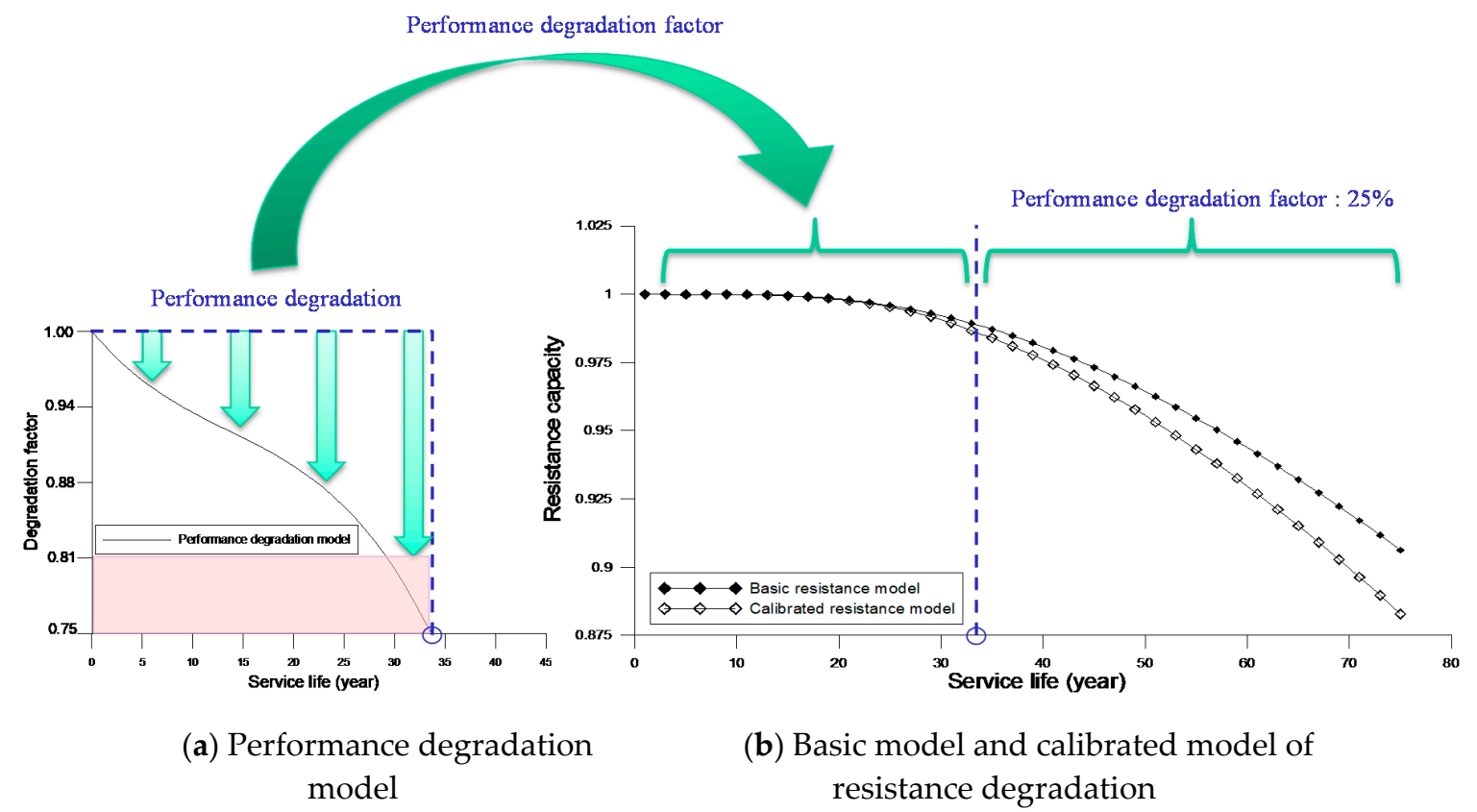

Figure 5. Calibration resistance model with performance degradation model.

\subsection{Calibration of the Standard Performance Degradation Model Considering Previous Inspections}

Table 6 outlines the previous inspection results of bridge members whose condition levels are assumed to rapidly decline, when compared to the standard performance degradation model. The inspection results are obtained by assuming a sample of inspection results over 16 years after the bridge was completed, as well as a sample where only the 16th year inspection results were available (with no previous inspection results).

Table 7 outlines the previous inspection results of bridge members whose condition levels are assumed to decline, when compared to the standard performance degradation model, slowly. The inspection results are obtained based upon two assumptions: inspections over 28 years after the completion of the bridge and only two inspection results with a lack of previous inspections.

Figures 6 and 7 show the calibration results of the standard performance degradation model according to the previous inspection of bridge members assumed in Tables 6 and 7 . 


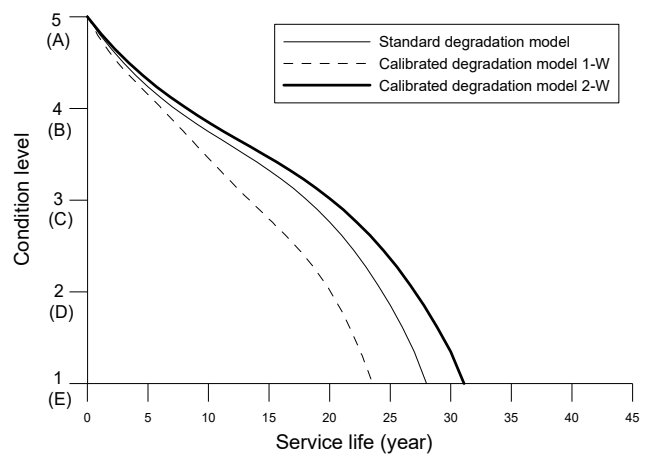

(a) With previous inspections

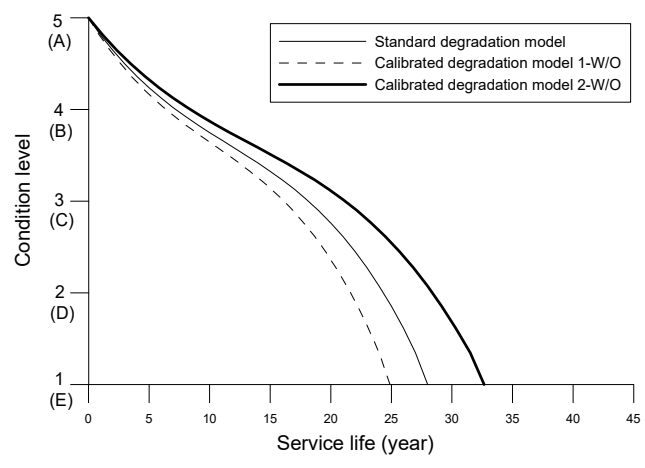

(b) Without previous inspections

Figure 6. Calibration of the performance degradation model of the RC slab.

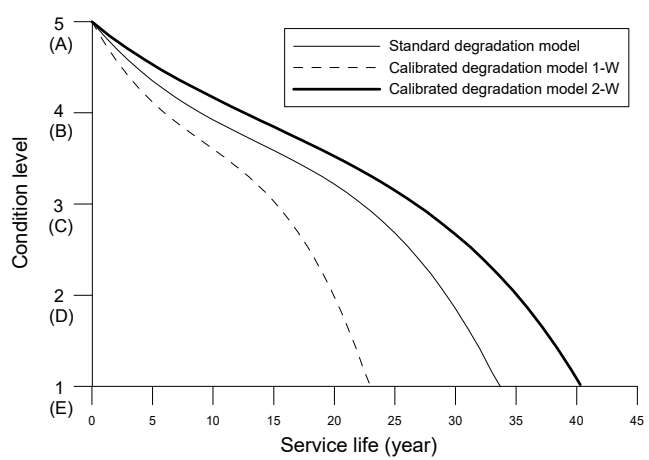

(a) With previous inspections

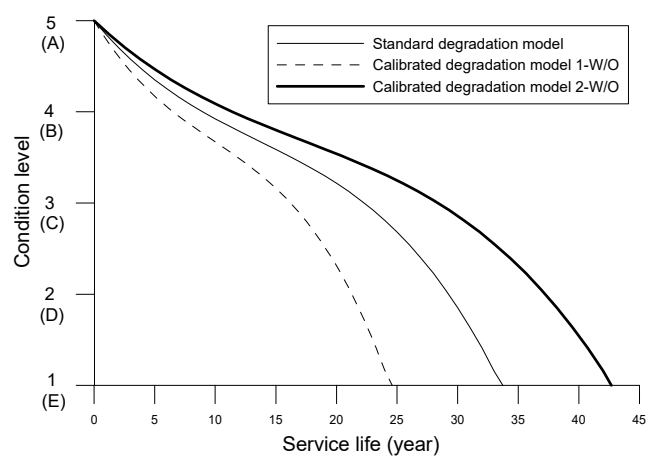

(b) Without previous inspections

Figure 7. Calibration of the performance degradation model of the PSC-I girder.

\section{Performance-Based Reliability Analysis Considering Site Environments}

\subsection{Effect of Previous Inspection Data}

The performance-based resistance deterioration model proposed in Section 3 is used to analyze the reliability by considering various site environments of the bridge. To estimate the effects of previous inspection results on the reliability of the bridge, the reliability is analyzed using the standard performance degradation model proposed in Section 3 and inspection data in Tables 5 and 6. The corrosive environment and traffic characteristics presented in Section 2 are also used. The corrosive environments considered are mild, normal, and severe, and the traffic characteristics considered are light, normal, and heavy.

Figures 8-10 show the calculated reliabilities of PSC-I girder bridges comprising all the previous inspection results based on a service lifespan of 75 years. The basic model presented in Section 2 represents the model that does not account for the inspection data. The standard model is a performance-based resistance deterioration model that applies the standard degradation model. The calibrated model 1-W represents the results of a previous inspection (1-W) in Table 6. The calibrated model 2-W represents the results of a previous inspection (2-W) in Table 7.

The initial reliability of the bridge was $3.65\left(P_{f}=1.3 \times 10^{-4}\right)$ with light traffic characteristics, $3.54\left(P_{f}=2.0 \times 10^{-4}\right)$ with normal traffic characteristics, and $3.45\left(P_{f}=2.8 \times 10^{-4}\right)$ with heavy traffic characteristics. These results show that traffic characteristics affect the reliability of the bridge.

In the case of normal corrosive environment with normal traffic characteristics and service lifespan of 75 years, the reliability is $3.02\left(P_{f}=1.3 \times 10^{-3}\right)$ for the basic model, $2.74\left(P_{f}=3.1 \times 10^{-3}\right)$ for the standard model, $2.63\left(P_{f}=4.2 \times 10^{-3}\right)$ for the calibrated model $(1-\mathrm{W})$, and $2.78\left(P_{f}=2.7 \times 10^{-3}\right)$ for the calibrated model (2-W). When compared with the basic model, the standard model showed an increase in the probability of failure by 2.4 times, the calibrated model (1-W) by 3.4 times, and the 
calibrated model (2-W) by 2.2 times. These results suggest that inspection results affect the reliability analysis of the bridge.

Based on the service lifespan of 75 years, the calibrated model (1-W) with normal traffic characteristics had a reliability of $3.02\left(P_{f}=1.3 \times 10^{-3}\right)$ in a mild corrosion environment, 2.63 $\left(P_{f}=4.2 \times 10^{-3}\right)$ in a normal corrosion environment, and $2.13\left(P_{f}=1.7 \times 10^{-2}\right)$ in a severe corrosion environment. These results show that, given the same traffic characteristics, the reliability of bridges is influenced by different degrees of corrosive environments.

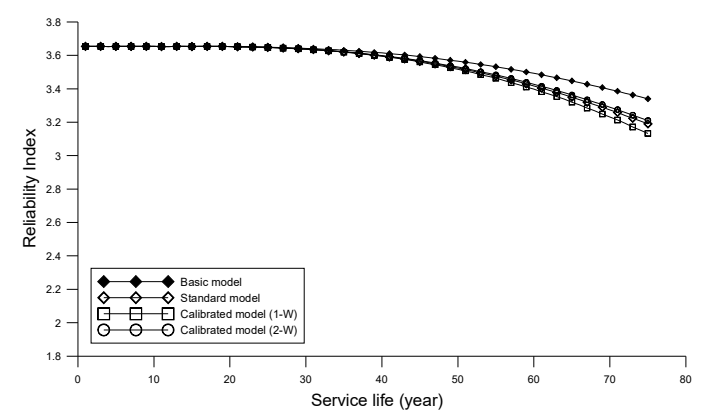

(a) Mild corrosion environment

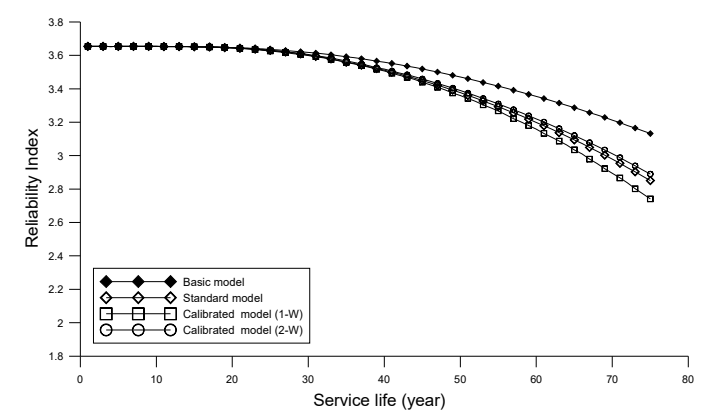

(b) Normal corrosion environment

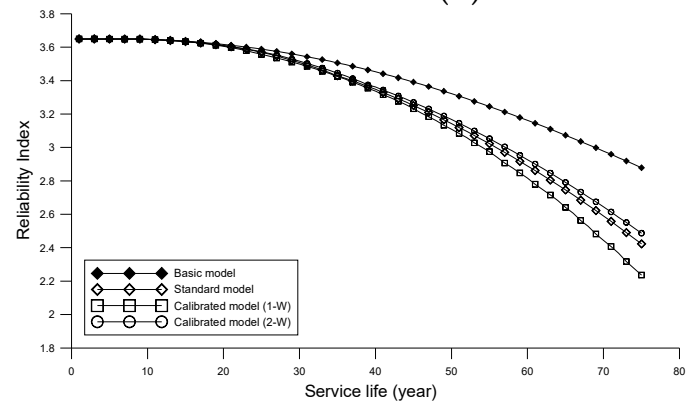

(c) Severe corrosion environment

Figure 8. Reliability degradation under light traffic characteristics (with previous inspection).

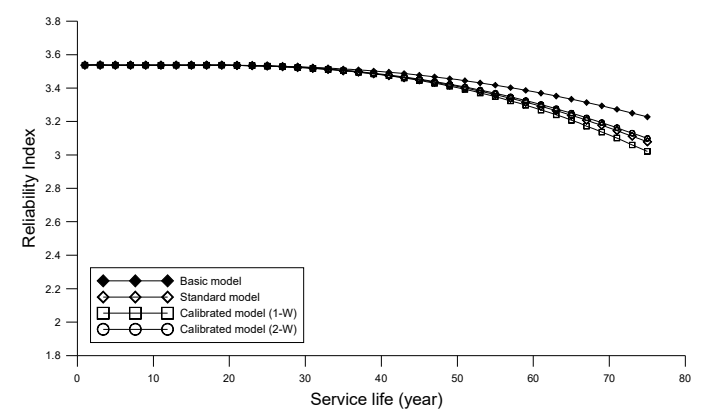

(a) Mild corrosion environment

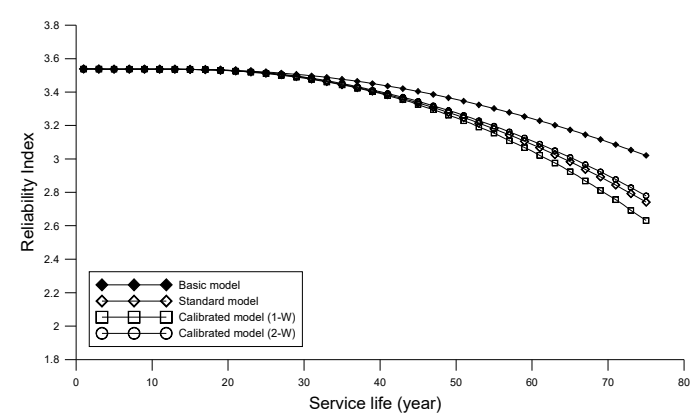

(b) Normal corrosion environment

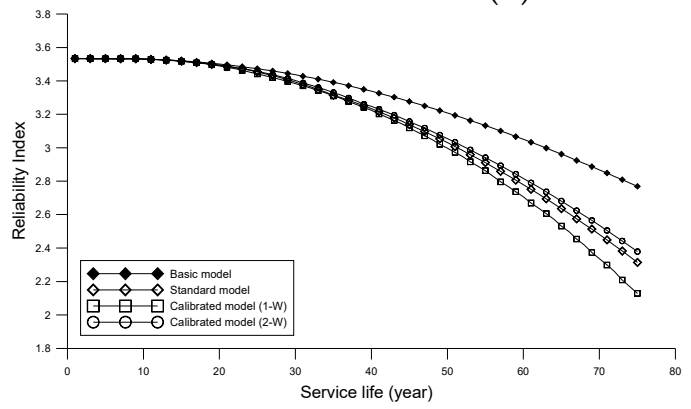

(c) Severe corrosion environment

Figure 9. Reliability degradation under normal traffic characteristics (with previous inspection). 


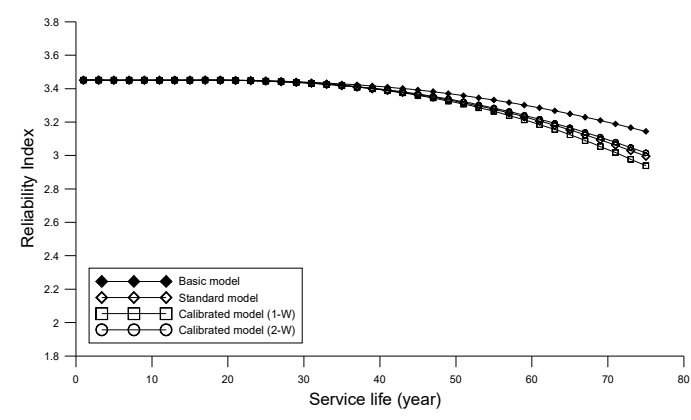

(a) Mild corrosion environment

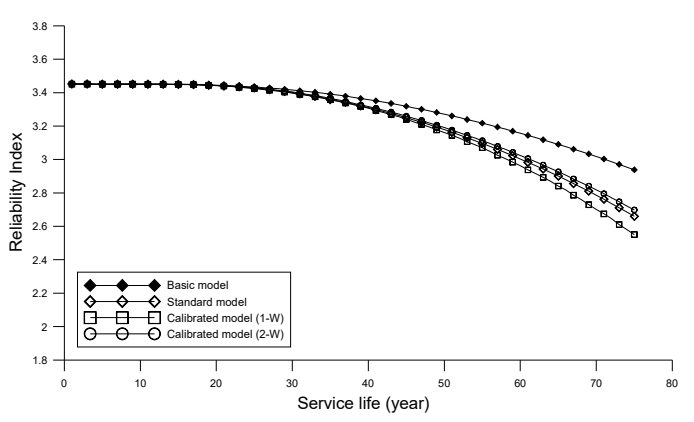

(b) Normal corrosion environment

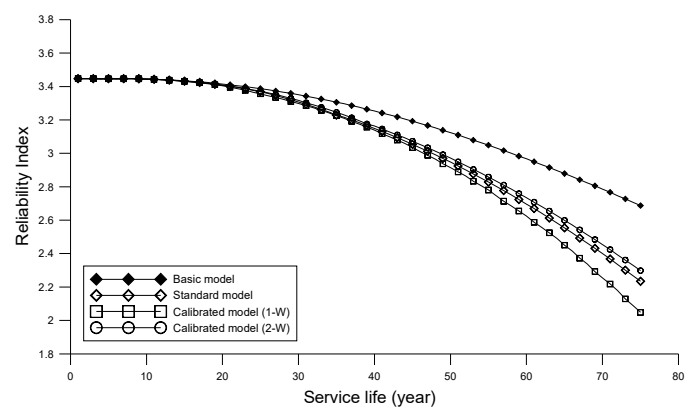

(c) Severe corrosion environment

Figure 10. Reliability degradation under heavy traffic characteristics (with previous inspection).

Figures 11-13 show the analyzed reliabilities of the PSC-I girder bridges based on a 75-year service lifespan with only one or two inspection results (in cases where there are insufficient or no previous inspection data). The calibrated model (1-W/O) reflects the calibrated degradation model, whose condition level declined more quickly than that of the standard degradation model. The calibrated model (2-W/O) reflects the calibrated degradation model, whose condition level declined more slowly than that of the standard degradation model.

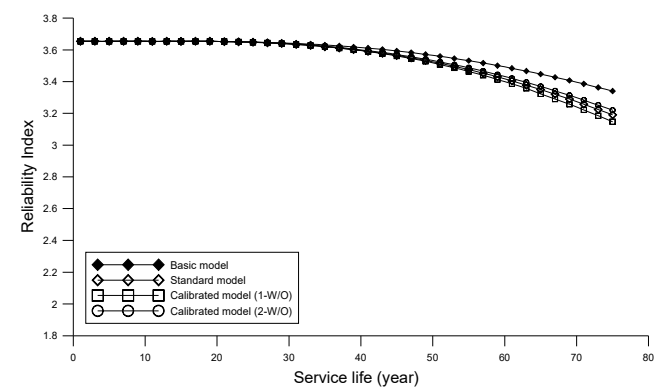

(a) Mild corrosion environment

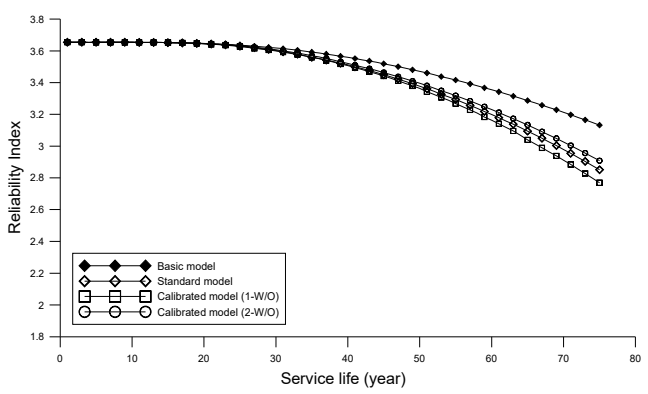

(b) Normal corrosion environment

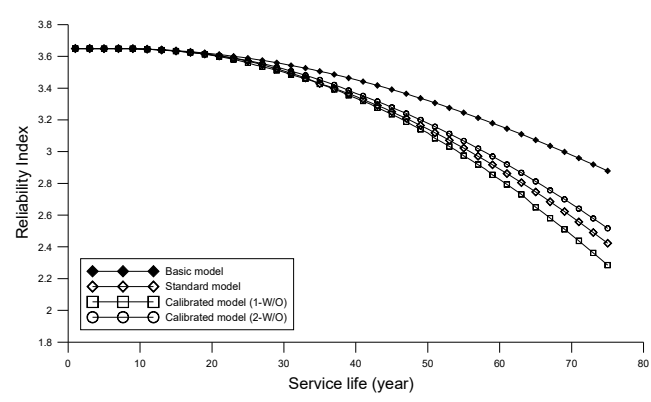

(c) Severe corrosion environment

Figure 11. Reliability degradation under light traffic characteristics (without previous inspection). 


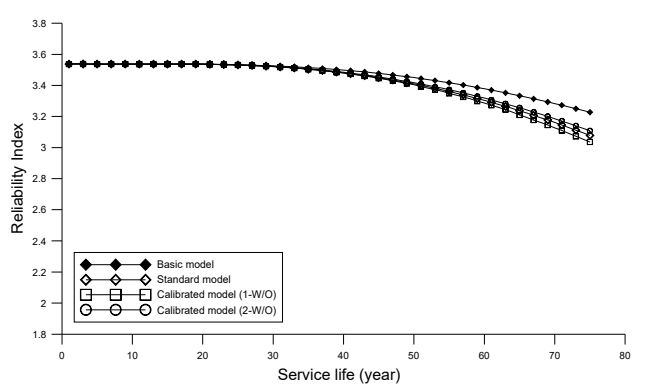

(a) Mild corrosion environment

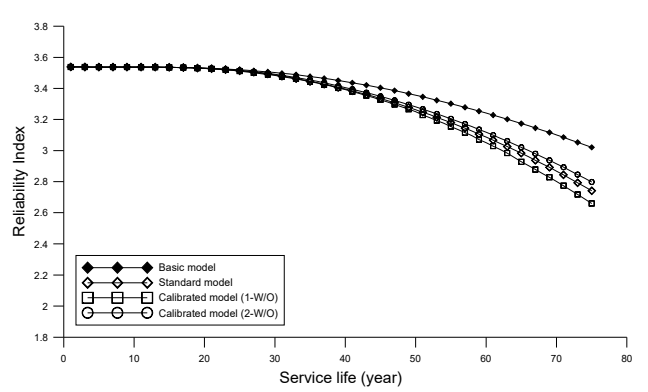

(b) Normal corrosion environment

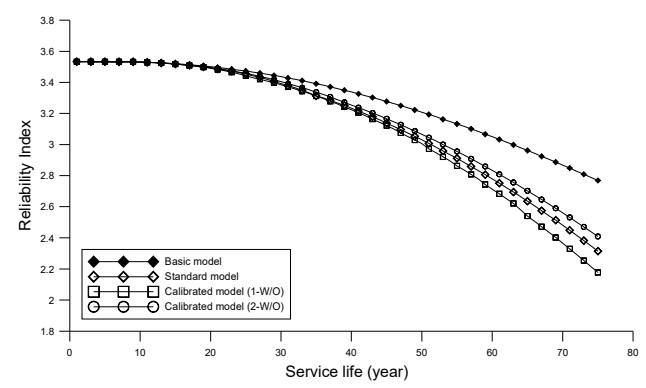

(c) Severe corrosion environment

Figure 12. Reliability degradation under normal traffic characteristics (without previous inspection).

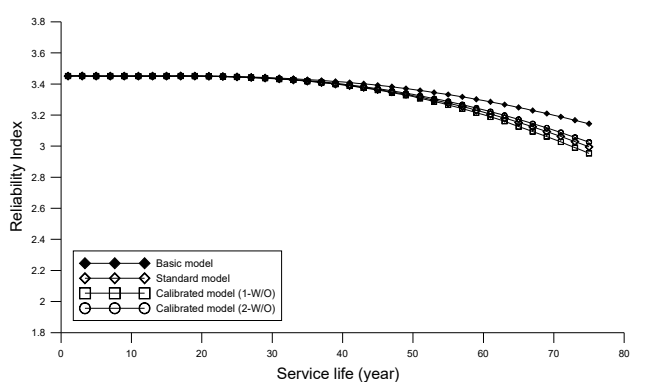

(a) Mild corrosion environment

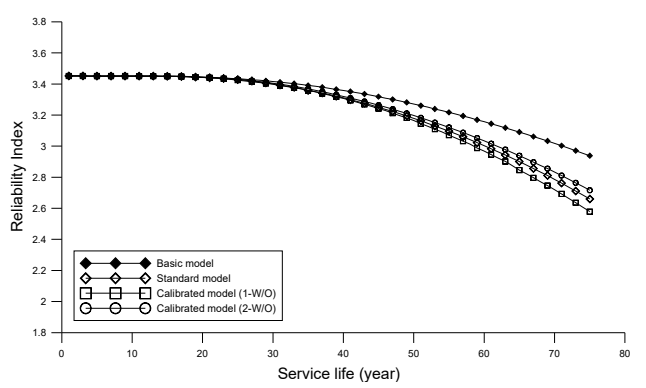

(b) Normal corrosion environment

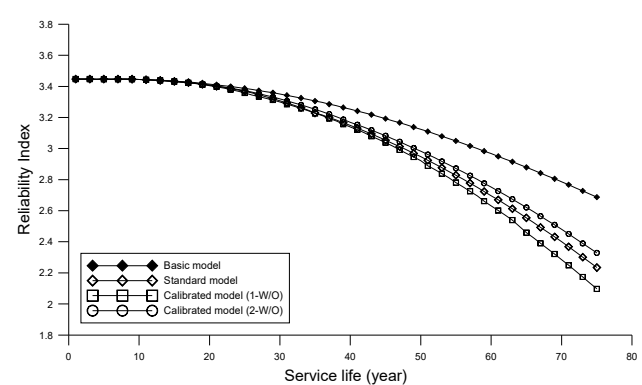

(c) Severe corrosion environment

Figure 13. Reliability degradation under heavy traffic characteristics (without previous inspection).

In the case of a normal corrosive environment with normal traffic characteristics and service lifespan of 75 years, the reliability was $3.02\left(P_{f}=1.3 \times 10^{-3}\right)$ for the basic model, $2.74\left(P_{f}=3.1 \times 10^{-3}\right)$ for the standard model, $2.66\left(P_{f}=3.9 \times 10^{-3}\right)$ for the calibrated model $(1-\mathrm{W} / \mathrm{O})$, and $2.80\left(P_{f}=2.6 \times 10^{-3}\right)$ for the calibrated model (2-W/O). When compared with the basic model, the standard model showed an increase in the probability of failure by 2.4 times, the calibrated model $(1-\mathrm{W} / \mathrm{O})$ by 3.1 times, and the calibrated model $(2-\mathrm{W} / \mathrm{O})$ by 2.0 times.

Based on the service lifespan of 75 years, the calibrated model $(1-\mathrm{W} / \mathrm{O})$ with normal traffic characteristics had a reliability of $3.04\left(P_{f}=1.2 \times 10^{-3}\right)$ in a mild corrosion environment, $2.66\left(P_{f}=3.9 \times\right.$ $\left.10^{-3}\right)$ in a normal corrosion environment, and $2.18\left(P_{f}=1.5 \times 10^{-2}\right)$ in a severe corrosion environment. 
According to Figures 8-13, for a service lifespan of 75 years, the difference in reliability between the calibrated model $(1-\mathrm{W})$ and calibrated model $(1-\mathrm{W} / \mathrm{O})$ is approximately $5-9 \%$, while the difference in reliability between the calibrated model $(2-W)$ and calibrated model $(2-W / O)$ is approximately $3-8 \%$. These results suggest that although previous inspection results have an impact on the reliability estimates of bridges, they are not very sensitive to the availability of previous inspection data as long as the calibrated performance degradation model includes current performance conditions. This also implies that the proposed calibrated method can provide a stable performance degradation model that does not rely too heavily on previous inspection data.

\subsection{Effect of Crack on Concrete Members}

To estimate the influence of cracks in concrete members on the reliability of bridges, a reliability analysis is carried out with the calibrated model (1-W) proposed in Section 4.1. Figures 14-16 show the reliability analysis results of the calibrated model (1-W) according to the traffic characteristics, corrosive environment, and crack width. It is assumed that the cracks of the calibrated model (1-W) appeared 16 years after the completion of its construction. In the case of light traffic characteristics with a crack width of $0.1-0.3 \mathrm{~mm}$ and service lifespan of 75 years, the reliability was analyzed to be 2.90 $\left(P_{f}=1.9 \times 10^{-3}\right)$ to $2.56\left(P_{f}=5.3 \times 10^{-3}\right)$ in a mild corrosion environment, $2.59\left(P_{f}=4.9 \times 10^{-3}\right)$ to 2.34 $\left(P_{f}=9.8 \times 10^{-3}\right)$ in a normal corrosion environment, and $2.18\left(P_{f}=1.5 \times 10^{-2}\right)$ to $2.06\left(P_{f}=2.0 \times 10^{-2}\right)$ in a severe corrosion environment.

In the case of normal traffic characteristics with a crack width of $0.1-0.3 \mathrm{~mm}$ and service lifespan of 75 years, the reliability was analyzed to be $2.79\left(P_{f}=2.6 \times 10^{-3}\right)$ to $2.45\left(P_{f}=7.2 \times 10^{-3}\right)$ in a mild corrosion environment, $2.48\left(P_{f}=6.6 \times 10^{-3}\right)$ to $2.23\left(P_{f}=1.3 \times 10^{-2}\right)$ in a normal corrosion environment, and $2.07\left(P_{f}=1.9 \times 10^{-2}\right)$ to $1.95\left(P_{f}=2.5 \times 10^{-2}\right)$ in a severe corrosion environment.

In the case of heavy traffic characteristics with a crack width of $0.1-0.3 \mathrm{~mm}$ and service lifespan of 75 years, the reliability was analyzed to be $2.71\left(P_{f}=3.4 \times 10^{-3}\right)$ to $2.37\left(P_{f}=9.0 \times 10^{-3}\right)$ in a mild corrosion environment, $2.40\left(P_{f}=8.3 \times 10^{-3}\right)$ to $2.15\left(P_{f}=1.6 \times 10^{-2}\right)$ in a normal corrosion environment, and $1.99\left(P_{f}=2.3 \times 10^{-2}\right)$ to $1.87\left(P_{f}=3.0 \times 10^{-2}\right)$ in a severe corrosion environment.

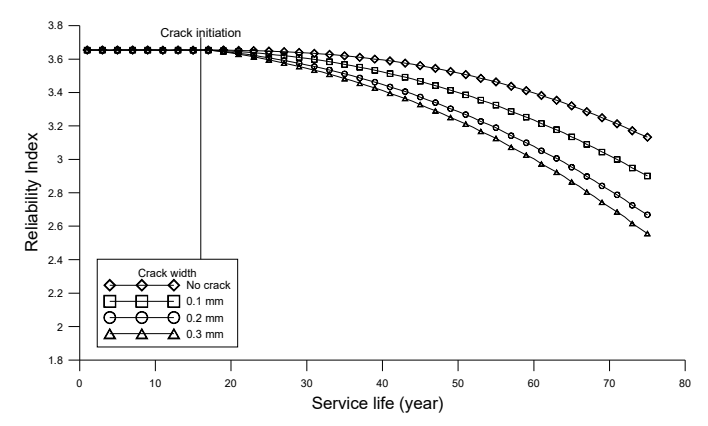

(a) Mild corrosion environment

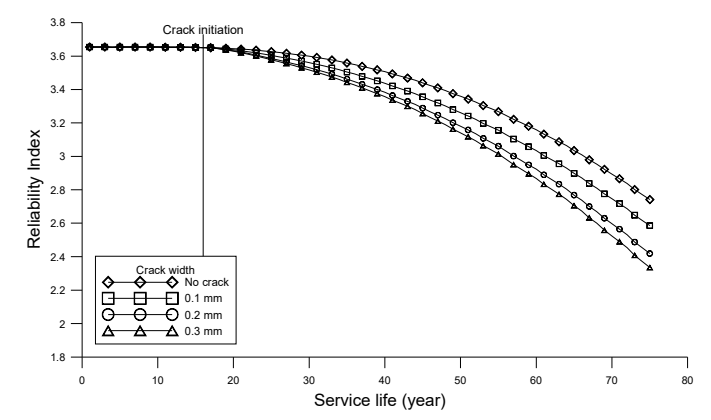

(b) Normal corrosion environment

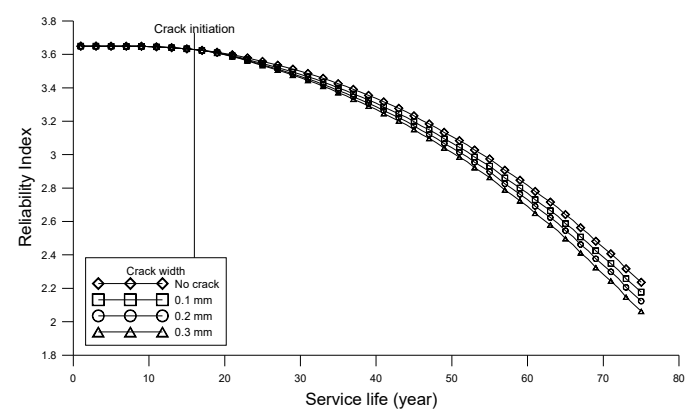

(c) Severe corrosion environment

Figure 14. Reliability degradation considering crack width under light traffic characteristics (calibrated model (1-W)). 


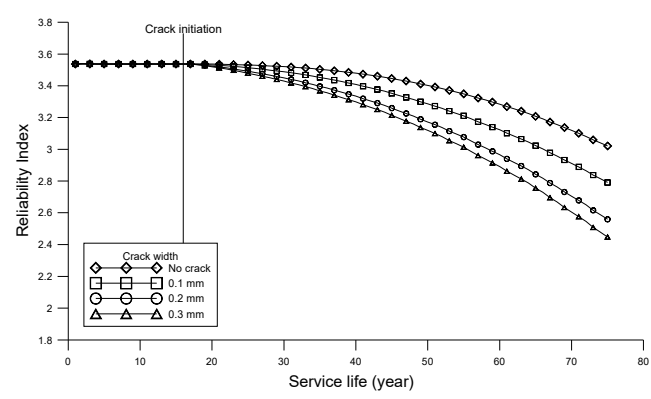

(a) Mild corrosion environment

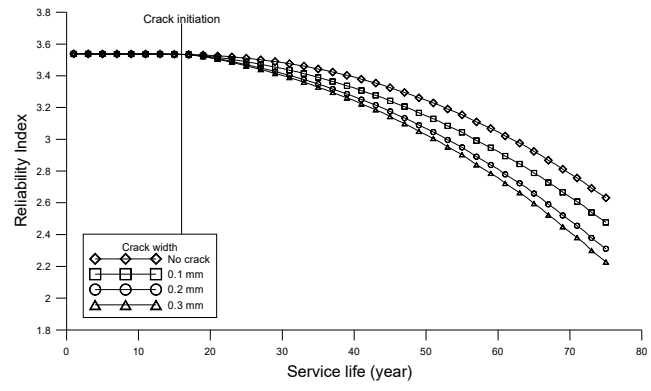

(b) Normal corrosion environment

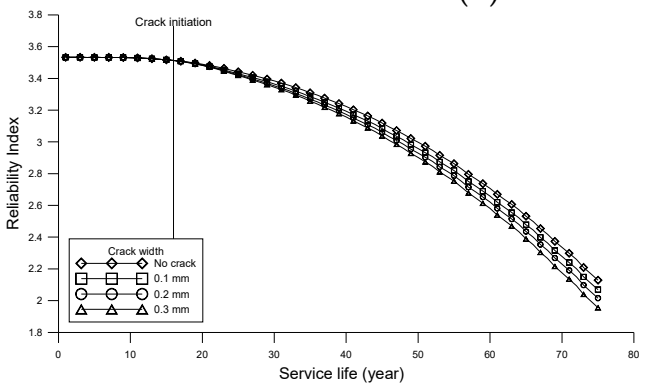

(c) Severe corrosion environment

Figure 15. Reliability degradation considering crack width under normal traffic characteristics (calibrated model (1-W)).

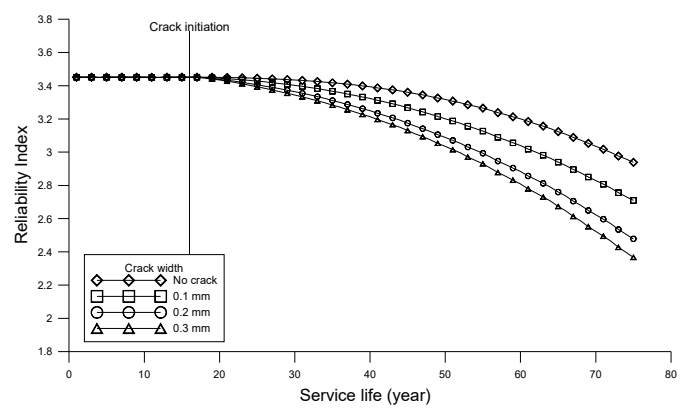

(a) Mild corrosion environment

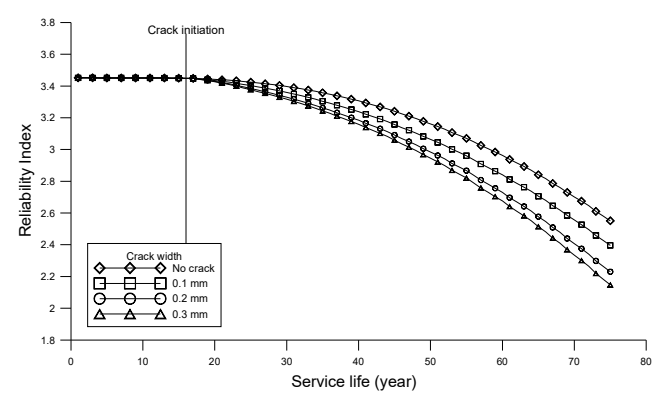

(b) Normal corrosion environment

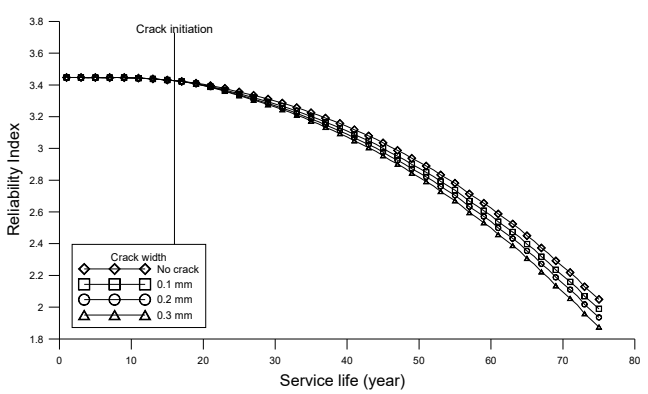

(c) Severe corrosion environment

Figure 16. Reliability degradation considering crack width under heavy traffic characteristics (calibrated model (1-W)).

Based on Figures 14-16, given the same traffic characteristics; if the corrosive environment becomes severe, and the width of the cracks in the concrete members increases, the reliability decreases. These results suggest that the traffic characteristics, corrosive environment, and crack width in concrete members influence the reliability analysis results of the bridge.

Figures 17-19 show the reliability analysis results of the calibrated model (2-W) according to the traffic characteristics, corrosive environment and crack width. It is assumed that the cracks of the calibrated model $(2-W)$ appeared 26 years after the completion of its construction. In the case of light 
traffic characteristics with a crack width of $0.1-0.3 \mathrm{~mm}$ and service lifespan of 75 years, the reliability was analyzed to be $3.05\left(P_{f}=1.1 \times 10^{-3}\right)$ to $2.83\left(P_{f}=2.3 \times 10^{-3}\right)$ in a mild corrosion environment, 2.80 $\left(P_{f}=2.5 \times 10^{-3}\right)$ to $2.65\left(P_{f}=4.0 \times 10^{-3}\right)$ in a normal corrosion environment, and $2.46\left(P_{f}=6.9 \times 10^{-3}\right)$ to $2.39\left(P_{f}=8.3 \times 10^{-3}\right)$ in a severe corrosion environment.

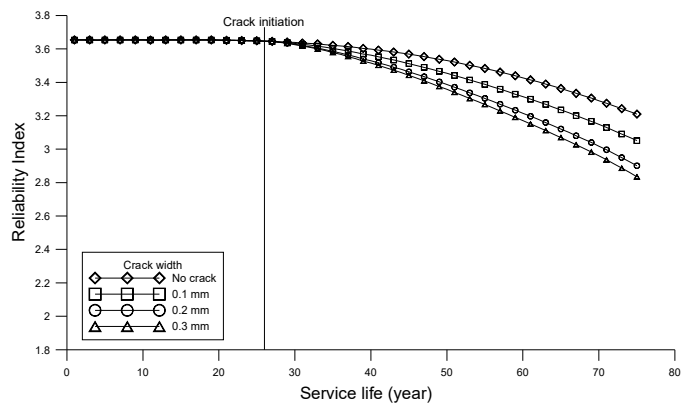

(a) Mild corrosion environment

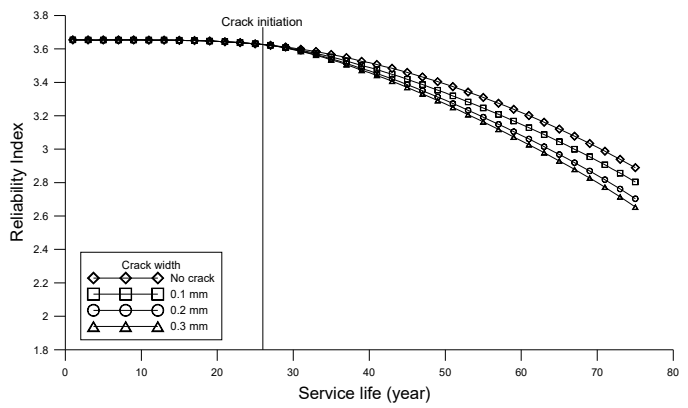

(b) Normal corrosion environment

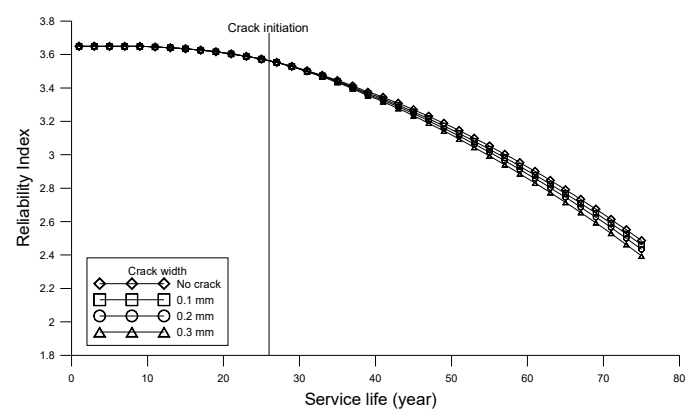

(c) Severe corrosion environment

Figure 17. Reliability degradation considering crack width under light traffic characteristics (calibrated model (2-W)).

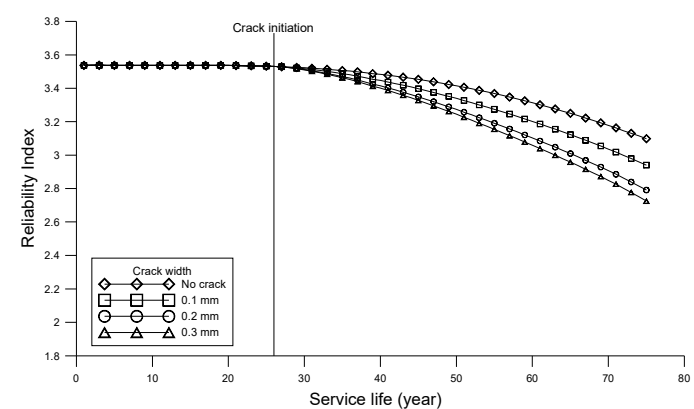

(a) Mild corrosion environment

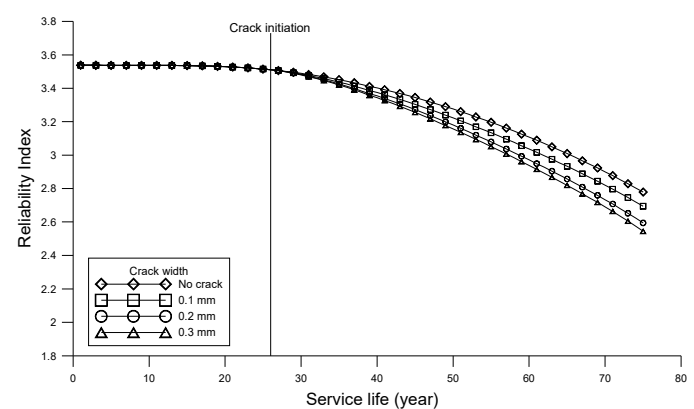

(b) Normal corrosion environment

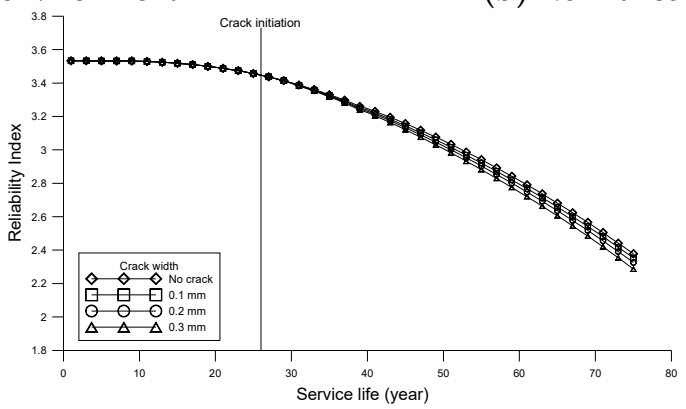

(c) Severe corrosion environment

Figure 18. Reliability degradation considering crack width under normal traffic characteristics (calibrated model (2-W)). 


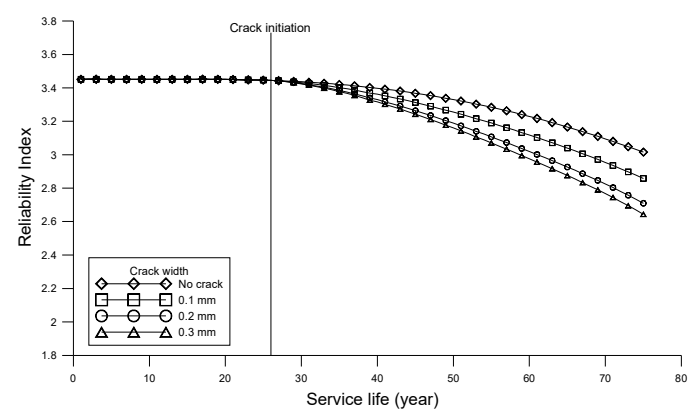

(a) Mild corrosion environment

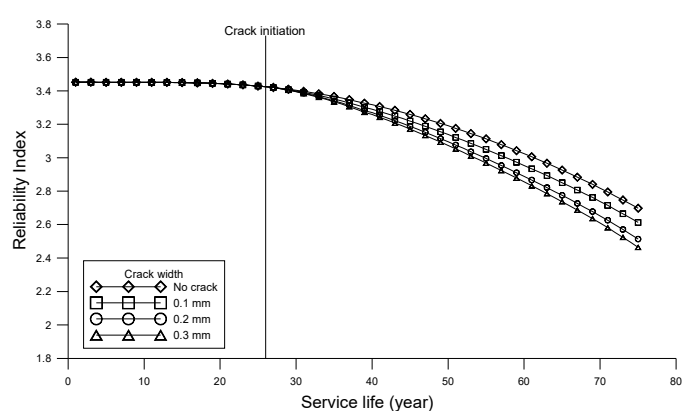

(b) Normal corrosion environment

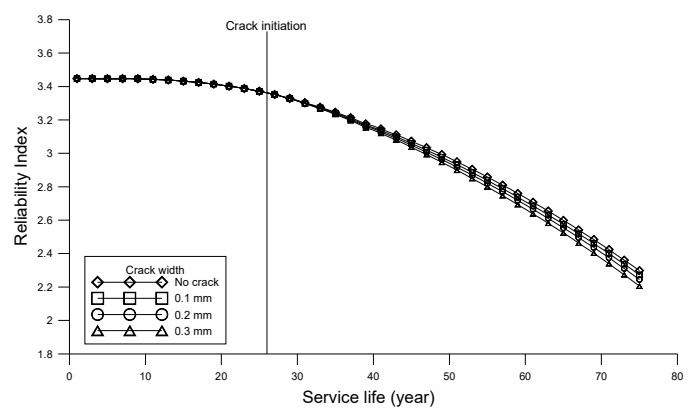

(c) Severe corrosion environment

Figure 19. Reliability degradation considering crack width under heavy traffic characteristics (calibrated model (2-W)).

In the case of normal traffic characteristics with a crack width of $0.1-0.3 \mathrm{~mm}$ and service lifespan of 75 years, the reliability was analyzed to be $2.94\left(P_{f}=1.6 \times 10^{-3}\right)$ to $2.72\left(P_{f}=3.2 \times 10^{-3}\right)$ in a mild corrosion environment, $2.69\left(P_{f}=3.5 \times 10^{-3}\right)$ to $2.54\left(P_{f}=5.5 \times 10^{-3}\right)$ in a normal corrosion environment, and $2.35\left(P_{f}=9.3 \times 10^{-3}\right)$ to $2.29\left(P_{f}=1.1 \times 10^{-2}\right)$ in a severe corrosion environment.

In the case of heavy traffic characteristics with a crack width of $0.1-0.3 \mathrm{~mm}$ and service lifespan of 75 years, the reliability was analyzed to be $2.86\left(P_{f}=2.1 \times 10^{-3}\right)$ to $2.64\left(P_{f}=4.1 \times 10^{-3}\right)$ in a mild corrosion environment, $2.61\left(P_{f}=4.5 \times 10^{-3}\right)$ to $2.46\left(P_{f}=6.9 \times 10^{-3}\right)$ in a normal corrosion environment, and $2.27\left(P_{f}=1.2 \times 10^{-2}\right)$ to $2.21\left(P_{f}=1.4 \times 10^{-2}\right)$ in a severe corrosion environment.

\section{Conclusions}

In this study, a method was proposed to develop a performance-based resistance deterioration model considering the calibrated standard performance degradation model of an in-service bridge, especially for aged bridges that require more rational maintenance. The PSC-I girder bridge was selected as a representational bridge.

The standard performance degradation model was calibrated using previous inspection data. A degradation factor was applied to the calibrated performance degradation model. This was then reflected in the basic resistance model as additional degradation of the resistance capacity. Through this process, the performance-based resistance deterioration model is developed, combining the performance degradation model based on bridge inspection results and the deterioration model of resistance capacity considering the corrosive environment. The performance-based resistance deterioration model was used to analyze the reliability by considering the various site environments of the bridge.

The basic model, which did not reflect the inspection data, the standard model, which was applied to the standard performance degradation model, and the calibrated model reflecting the inspection data, were analyzed in terms of reliability and were compared by considering a service lifespan of 75 years as the criterion. The inspection data of the calibrated model was applied to different cases in which the condition level declined quicker or slower than in the standard model. The standard 
model increased the probability of failure since its reliability became lower than that of the basic model. The reliability of the calibrated model was also lower than that of the basic model and varied above or below that of the standard model, depending on the inspection data. From these observations, it can be inferred that inspection results affect the reliability analysis of bridges.

To investigate whether there is a significant difference between the two cases where previous inspection data was sufficient and insufficient respectively, the reliability was evaluated with and without previous inspection data for comparison. It was found that the results of the cases for overall comparison are not considerably different for any site environment. These results indicate that the calibrated performance degradation model based on previous inspection results is not very sensitive to the availability of previous inspection data if the current performance state is included. This implies that the suggested calibration method does not rely heavily on previous inspection data, but can present a reliable performance degradation model. Further research is necessary to apply the proposed method to maintenance based on the timing of repair and life cycle cost analysis. This paper is based on excerpts from the doctoral dissertation of Heo [18].

Funding: This research received no external funding.

Conflicts of Interest: The author declares no conflicts of interest.

\section{References}

1. Ang, A.H.-S.; Cornell, C.A. Reliability bases of structural safety and design. ASCE J. Struct. Div. 1974, 100, 1769-1785.

2. Kameda, H.; Koike, T. Reliability theory of deteriorating structure. J. Struct. Div. 1975, 101, 295-310.

3. Yang, S.I.; Frangopol, D.M.; Neves, L.C. Optimum maintenance strategy for deteriorating bridge structures based on lifetime functions. Eng. Struct. 2006, 28, 196-206. [CrossRef]

4. Okasha, N.M.; Frangopol, D.M. Lifetime-oriented multi-objective optimization of structural maintenance considering system reliability, redundancy and life-cycle cost using GA. Struct. Saf. 2009, 31, 460-474. [CrossRef]

5. Wang, C.; Li, Q.; Ellingwood, B.R. Time-dependent reliability of ageing structures: An approximate approach. Struct. Infrastruct. Eng. 2016, 12, 1566-1572. [CrossRef]

6. Guo, Y.; He, X.; Peeta, S.; Weiss, W.J. Internal Curing for Concrete Bridge Decks: Integration of a Social Cost Analysis in Evaluation of Long-Term Benefit. Transp. Res. Rec. 2016, 2577, 25-34. [CrossRef]

7. Kim, S.H.; Choi, J.G.; Ham, S.M.; Heo, W.H. Reliability evaluation of a PSC highway bridge based on resistance capacity degradation due to a corrosive environment. Appl. Sci. 2016, 6, 423. [CrossRef]

8. Korea Highway Bridge Specifications (KHBS); Korea Institute of Bridge and Structural Engineers: Seoul, Korea, 2015.

9. AASHTO LRFD Bridge Design Specifications, 6th ed.; American Association of State Highway and Transportation Officials: Washington, DC, USA, 2012.

10. Kwon, S.J.; Na, U.J.; Park, S.H.; Jung, S.H. Service life prediction of concrete wharves with early-aged crack: Probabilistic approach for chloride diffusion. Struct. Saf. 2009, 31, 75-83. [CrossRef]

11. Withiam, J.L.; Voytko, E.P.; Barker, R.M.; Duncan, J.M.; Kelly, B.C.; Musser, S.C.; Elias, V. Load and Resistance Factor Design (LRFD) for Highway Bridge Substructures, FHWA HI-98-032; Federal Highway Administration: Washington, DC, USA, 1998.

12. Calibration of LRFD Bridge Design Code, NCHRP 368; Federal Highway Administration: Washington, DC, USA, 1999.

13. Nowak, A.S.; Szerszen, M.M. Calibration of design code for buildings (ACI 318): Part 1-Statistical models for resistance. Struct. J. 2003, 100, 377-382.

14. Development of Bridge. Maintenance Technique Considering Performance Based on the Site Environment; Korea Infrastructure Safety and Technology Corporation: Seoul, Korea, 2015.

15. Kim, S.H.; Heo, W.H.; Yu, D.W.; Choi, J.G. Analysis of Extreme Load Effects Based on Various Traffic Characteristics and Environments. In Proceedings of the Symposium on Reliability of Engineering System, Hangzhou, China, 15-17 October 2015. 
16. A Study on Extension of Service Life of Highway Bridge; Korea Infrastructure Safety and Technology Corporation: Seoul, Korea, 2000.

17. Standard for Structure Safety Inspection: Bridge. Structure, RD-12-E6-024; Korea Infrastructure Safety, and Technology Corporation: Seoul, Korea, 2012.

18. Heo, W.H. Performance-Based Optimal Maintenance System for Highway Bridges Considering Site Environments. Ph.D. Thesis, Yonsei University, Seoul, Korea, 2018; pp. 67-102. 